\title{
A CONCEPTUAL CONTRIBUTION TO RESEARCH ON STIMULATING SERVICE INNOVATION - THE INTERRELATION OF SERVICE INNOVATION AND CUSTOMER COMPLAINT MANAGEMENT
}

\author{
Julia Meik, Zeppelin University, Germany \\ Christian Brock, Zeppelin University, Germany
}

\begin{abstract}
Services can easily be imitated and depend on continuous innovation (e.g., Sundbo, 1997); hence service innovation is of strategic importance. Accordingly, service innovation has received considerable attention in the marketing literature (e.g., Storey \& Kahn, 2010; Ordanini \& Parasuraman, 2010; Umashankar, Srinivasan \& Hindman, 2011). The role of external knowledge integration to stimulate service innovations has been a topic among this research. Customers have been identified as an important knowledge source for services. Customers directly receive and benefit from service innovations (Hipp \& Grupp, 2005); this is why their ideas should be considered to foster innovations and to increase customer satisfaction. Research has so far focused on the direct integration of customers such as customer co-creation and its contributions to services and service innovation (e.g., Hoyer, Chandy, Dorotic, Krafft \& Singh, 2010; Melton \& Hartline, 2010; Chan, Yim \& Lam, 2010; Vargo \& Lusch, 2008). However, disadvantages of direct customer integration such as customers' limited mindset advancing only incremental, preventing radical innovations and its lack of formalization potential have come to the fore. Hence, recent research has claimed the importance of further examining customer integration into innovation processes (e.g., Ostrom, Bitner, Brown, Burkhard, Goul, et al. 2010).
\end{abstract}

Findings on indirect customer integration into service innovation processes demonstrate that especially the integration of customers' ideas in the initial stage of the innovation process provides information on customer needs (e.g., Magnusson, Matthing \& Kristensoon, 2003). Furthermore, indirect customer integration usually involves a combination of customer and employee knowledge because customer input has to be analyzed and interpreted by internal knowledge sources. Empirical findings show that employee integration into the innovation development process advances innovation performance (e.g., Odininani \& Parasuraman, 2010; Melton \& Hartline, 2010; Eisengerich, Rubera \& Seifert, 2009). Against this background this study focuses on customer complaints as a potential indirect form of customer integration. Customer complaints information analysis potential to stimulate service innovation has not been examined so far. However, recent studies have discussed the relevance of formalization potential in the innovation process (e.g., Ettlie \& Rosenthal, 2011). Formalization is seen as the beginning of knowledge creation since it leads to codification of knowledge. Customer complaint controlling could offer initial possibilities for formalization, since complaints can be categorized and accounts can be identified. Further but equally relevant, complainers show a high level of affective commitment to the service provider (e.g., Evanschitzky, Brock \& Blut, 2011). According to the theory of lead users (e.g., Franke, von Hippel \& Schreier, 2006) in manufacturing innovation development, complainers could be particularly qualified for and willing to invest into feedback because they benefit directly from contributing to service innovation processes.

Hence,!this conceptual study addresses gaps in current research on other more indirect forms of customer integration. First, while customer complaint handling and stimulation have received considerable attention in the marketing literature, research on customer complaint controlling and complaint information analysis has been largely neglected. In addition, analysis of complaint information to generate ideas for service innovation has not been examined and overlooked to date. Based on this current state of research, we develop a conceptual framework and investigate research questions focusing on the interrelation of two streams of research: service innovation and customer complaint management.

References available upon request.

Proceedings of AMS' World Marketing Congress Cultural Perspectives in Marketing (C 2012 